\title{
Complications During Needle Electromyography; A Study Done for Twenty Years
}

\author{
Muniba Fayyaz ${ }^{1 *}$ and Rollin J Hawley² \\ ${ }^{1}$ Department of Medicine, Pakistan \\ ${ }^{2}$ Department of Neurology, USA
}

Submission: January 17, 2019; Published: April 22, 2019

*Corresponding author: Muniba Fayyaz, Department of Medicine, Shadman Rd, Ichra, Lahore, Punjab 54000, Pakistan

\begin{abstract}
Background: The objective of this study was to identify the complications and their relationship with the patients past medical history in patients undergoing needle EMG study over a duration of twenty years.

Method: Our data included both EMG and clinical information on patients. It was collected from August 27, 1998-February 08, 2018 in a Neurology Clinic at Carilion New River Valley Medical Center in 10,063 patients undergoing needle EMG study.

Results: Out of 10,063 patients who underwent EMG, only 191 (1.89\%) patients experienced a complication. Out of these 191 patients, presyncope accounted for a total of 182 (95.3\%), 4 (2.09\%) syncope, 3 convulsive syncopes $(1.57 \%), 1(0.52 \%)$ pneumothorax and $1(0.52 \%)$ complication was the examiner experiencing a needle stick injury. There was no significant relationship between the patients past medical history and the type of complication occurring.
\end{abstract}

Conclusion: Complications during an EMG are highly unlikely, and it is relatively a safe procedure provided that a standard technique is used by the examiner.

Keywords: Electromyography; Syncope; Presyncope; Pneumothorax; Needle injury

Abbreviations: EMG: Electromyography

\section{Introduction}

Needle electromyography (EMG) is performed in patients to evaluate for any suspected neuromuscular disorders. This procedure is invasive and although usually safe can be associated with complications. The most common complications include mild discomfort and bleeding [1]. During the past other complications have also been reported some which include infections, hematomas and pneumothorax. If this procedure is performed properly many of these complications can be prevented and the patient does not have to be informed of them, unless there is a situation where these hazards cannot be prevented [2]. We have conducted a study to determine the different types of complications that occurred in a population of 10,063 patient's EMG procedure during a period of twenty years in a neurology clinic. The aim of this study is to [1]. determine the type and frequency of complications occurring in these patients [2]. describe additional characteristics which can be attributed to these complications.

\section{Materials \& Methods}

Our study was conducted from February 06, 2018 - August 28 , 1998, in 10,063 patients who underwent EMG for the assessment of neuromuscular disorders. The data was taken from a neurology clinic in Carilion New River Valley Medical Center, VA USA. It was stored and maintained in the clinic throughout this time period. The data included every patient undergoing EMG during this time frame and was double checked by the authors to confirm that all patients who underwent a complication during the EMG procedure were included. The data was analyzed in May 2018 and every individual patient's information stated above was charted on an excel sheet. The statistics were then calculated and double checked by the authors to eliminate any measured errors. The statistics were analyzed for [1-3]. Age, gender blood pressure after completing the study [4], part of body examined during the procedure [5], type of complication occurring during the EMG [6], the frequency of complication [7], treatment of the complication $[8,9]$. And the patient's clinical history that could be attributed in relation to the complication.

\section{Results}

After statistically analyzing the data we found that out of the 10,063 patients undergoing EMG during the period of twenty years, $191(1.89 \%)$ patients experienced a complication while 
performing the needle EMG study. Out of the 191 patients, there were 102 (53\%) females and 89 (46.6\%) males and their age ranged from 17-82 years (mean age: 45.13 years). There were 173 (90.6\%) upper limb EMG studies, 12 (6.3\%) lower limb EMG studies, 5 (2.6\%) combined upper and lower limbs and 1 $(0.5 \%)$ blink reflex study. The muscle that caused most of the symptoms was the paraspinal cervical muscles and the rest of the muscles included the deltoids, first interosseous, abductor digiti minimi, triceps, biceps, brachioradialis, flexor digitorum profundus, flexor carpi ulnaris, flexor carpi radialis and extensor digitorum communis. From the total number of complications presyncope accounted for a total of 182 (95.3\%) patients. Of the remaining 9 patients, 4 (2.09\%) experienced a brief syncope, 3 briefs convulsive syncopes (1.57\%), $1(0.52 \%)$ pneumothorax and finally $1(0.52 \%)$ complication was the examiner getting a needle stick injury [1]. Out of the 182 patients who experienced a presyncope, 11 (6.04\%) had orthostatic hypotension, 25 (13.7\%) were diabetics, 4 (2.2\%) had cardiac disease, 41 (22.5\%) were on antihypertensives and 11 (6.04\%) patients had a history of presyncope in the past due to needles. These patients were asked to lay down, some with their legs raised, eventually recovering completely. Overall, 18 patients refused further needle pricking [2].

\section{Discussion}

Table 1: Characteristics of the different complications during our EMG study.

\begin{tabular}{|c|c|c|c|c|c|c|}
\hline & N (\%) & M: F & Age Range & $\begin{array}{c}\text { No. Of Patients } \\
\text { With Orthostatic } \\
\text { Hypotension }\end{array}$ & Significant PMH & Treatment \\
\hline Presyncope & $182(95.3 \%)$ & $85: 97$ & $17-82$ & $11(6.04 \%)$ & $\begin{array}{c}\text { Diabetics }(25 ; 13.7 \%) \text { Cardiac Problems } \\
(4 ; 2.2 \%) \text { Antihypertensives }(41 ; 22.5 \%) \\
\text { History of presyncope due to needles } \\
(11 ; 6.04 \%)\end{array}$ & $\begin{array}{c}\text { Patient asked to lay } \\
\text { down; recovered }\end{array}$ \\
\hline Syncope (Brief) & $4(2.09 \%)$ & $2: 02$ & $39-71$ & None & $\begin{array}{c}\text { Patient asked to lay } \\
\text { down; recovered }\end{array}$ \\
\hline $\begin{array}{c}\text { Convulsive } \\
\text { Syncope (Brief) }\end{array}$ & $3(1.57 \%)$ & $1: 02$ & $29-41$ & $1(33 \%)$ & $\begin{array}{c}\text { No history of seizures Antihypertensives } \\
(1 ; 33 \%) \text { History of presyncope due to } \\
\text { needles (1; 33\%) }\end{array}$ & $\begin{array}{c}\text { Patient asked to lay } \\
\text { down; recovered }\end{array}$ \\
\hline $\begin{array}{c}\text { Pneumothorax } \\
\text { Examiner needle } \\
\text { Stick injury }\end{array}$ & $1(0.52 \%)$ & $0: 01$ & 33 & None & No history of smoking, lung disease & $\begin{array}{c}\text { Patient sent to ER for } \\
\text { treatment }\end{array}$ \\
\hline
\end{tabular}

$\%=$ Frequency of events, $\mathrm{M}=$ Males, $\mathrm{F}=$ Females, $\mathrm{PMH}=$ Past Medical History, $\mathrm{ER}=$ Emergency Room

Our study demonstrated that out of 10,063 EMG studies during the period of 20 years, only 191 patients experienced a complication. This shows that there was only a small $(1.89 \%)$ risk of developing a complication in twenty years of performing EMG procedures within this clinic. From the whole population, the most frequent complication was presyncope $(182 ; 1.8 \%)$, and other complications such as, syncope $(4 ; 0.04 \%)$, convulsive syncope $(3 ; 0.03 \%$;), pneumothorax $(1 ; 0.01 \%)$ and the examiner getting a needle stick injury $(1 ; 0.01 \%)$ were rare. There was no major clinical pattern; however, in patients experiencing
The $4(2.09 \%)$ patients who experienced a brief syncope episode did not have a past history of a similar episode or any significant clinical risk factors. They were also kept in the clinic laying down until they were conscious and fully recovered [3]. The $3(1.57 \%)$ patients who experienced a convulsive syncope had no past medical history of seizures. From these patients 1 (33\%) had orthostatic hypotension, 1 (33\%) had a history of presyncope, $1(33 \%)$ was on antihypertensives and 2 patients declined further testing. These patients were asked to lay down with their airways protected. The convulsive syncope lasted less than a minute and they eventually recovered [4]. In addition, $1(0.52 \%)$ patient experienced a pneumothorax after leaving the clinic once the EMG procedure was completed. This patient returned to the clinic after thirty minutes complaining of rightsided pleuritic chest pain, cough with mucus and a tender right pectoralis major muscle. This incident occurred due to the pricking of the right cervical paraspinalis muscle. The patient was sent to the ER and kept overnight with nonrebreathing oxygen therapy and was discharged with follow up once improved. This patient had no history of lung disease and was a non-smoker [5]. The last $1(0.52 \%)$ complication included the examiner needle sticking himself with a needle while performing EMG. presyncope certain important points were noted. One of the diabetic patients did not eat anything in the morning and juice was given to prevent hypoglycemia. Other patient's clinical history of diabetes mellitus, orthostatic hypotension, taking antihypertensives, cardiac history and a history of presyncope were significant. Studies have shown that autonomic neuropathy producing postural hypotension in diabetics, orthostatic hypotension due to other causes and orthostatic hypotension produced by taking antihypertensives could be a cause of syncope [3-5]. Also, patients with a cardiac history and a history 
of presyncope from needles due to low pain threshold could be another risk factor in contributing to a presyncope episode [6,7].

As shown in Table 1, females experienced presyncope more than men. In Park J et al. [8] did a study to determine the gender differences in patients with recurrent neurally mediated syncope. This study concluded that female patients were more prone to experience syncopal episodes for longer periods of their lives and more episodes of syncope than seen in male patients [8]. In addition, our study showed that in patients experiencing syncope, there was no significant past medical history or a similar episode occurring in the past. In patients with convulsive syncope, there was also no past history of seizures, however, orthostatic hypotension in one patient, antihypertensives and past history of presyncope in others could contribute to this event. As supported by previous studies, orthostatic hypotension due to different causes, and patients taking antihypertensives leading to orthostatic hypotension has been shown in syncope $[4,5]$. The patient with pneumothorax did not have any significant past medical history of lung disease or smoking and lastly, in the event of the examiner being needle struck, the incident was not reported, and the patient was not tested for infectious disease. Furthermore, we did not observe any pattern in the type of muscle needled accounting for the complications, however, upper limb (173) EMG accounted for most of the complications when compared to lower limbs $[9,10]$.

In the past, these similar complications have been reported in other studies. One study conducted at the Mayo Clinic, Rochester illustrated that pneumothorax had occurred in a total of 7 patients out of 64,490 patients who had undergone EMG, the most common muscles that caused this event were serratus anterior and diaphragm [9]. Cervical root stimulation and supraspinatus muscles have also been reported to cause pneumothorax in the past $[10,11]$. Paracervical muscles needle insertion, similar to our patient, have been addressed in the past to cause pneumothorax [12]. In 2008, there was a study done to determine the frequency of needlestick injuries among electromyographers. This study concluded that out of 880 physicians who responded to their survey, $64 \%$ of these physicians had experienced at least one needlestick injury during EMG and 8\% had reported five or more injuries. Needlestick injuries that had been contaminated with an infectious disease (hepatitis C, B and HIV/AIDS) occurred in 1 in every 11 physicians who experienced needle stick injury. However, nearly $44 \%$ of the physicians did not report at least one needle stick injury to the official's centers. It was stated that the most common preventive reason for injury was a perceived lack of time [13].

In our study the examiner also did not report the incidence to officials and did not test the patient or himself for any infectious disease even though it is strongly recommended that a physician should always report the injury. To our knowledge, studies in which complications such as presyncope, syncope, and convulsive syncope have not been reported in the past during the EMG procedure, however, an article written by Gechev A et al. [14] stated that presyncope and syncope are well known to Electromyographers, although are relatively uncommon $(<1 / 100)$ complications [14]. It is also worth mentioning that complications not occurring in our data are also important and should be kept in mind. An example of this includes hematomas occurring in patients taking anticoagulants (especially if they are overweight) and may require prolonged local pressure. In the past paraspinal hematomas have been reported [2]. Finally, in patients with cardiac pacemakers, implanted cardioverter, defibrillators and electrically conductive lines that end in the chest should not be crossed with sources of current which include ground lines. If these patients were to be tested it is suggested to place all electrodes (including ground) to one extremity without crossing cardiac devices or their wires and conductive lines. Also, in such patients the use to maximal durations of stimulus current should be $0.2 \mathrm{msec}$ and stimulation rates no more than one Hertz. If the technician comes across an unstable patient, then the manufacturer's technician could temporarily disconnect the defibrillator and the patient be tested by a cardiologist monitoring the heart. Special care should be taken in electrical safety in all patients, including grounding, especially in the intensive care unit. Wooden tables should be used in the EMG laboratory [2].

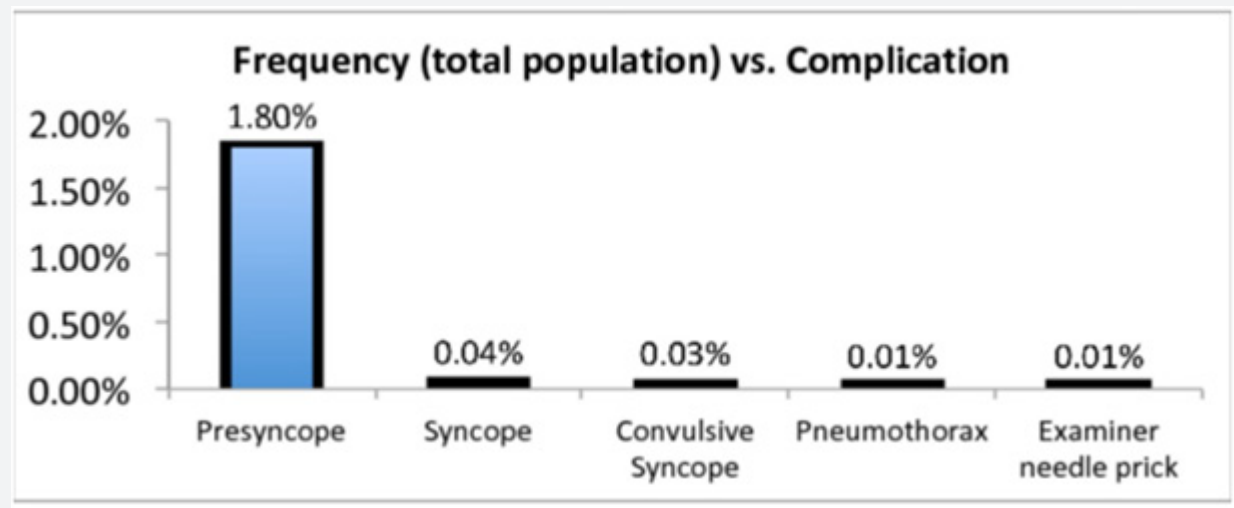

Figure 1: Frequency (\%) of the complications from the whole population. 
Moreover, our study did have limitations that must be recognized. Since our study was conducted in a small neurology clinic, it cannot be generalized to the whole population. Also, a small amount of the data was lost during these periods of years. Our study was also performed by one examiner using the same machine for the duration of the twenty years. This can lead to flaws in the study since in the event of producing an error the same examiner and machine can repeat it over the years. In contrast, in our study error can be minimized since there were not many different examiners or machines performing the procedure. Our study was conducted for a duration of twenty years in over 10,000 patients; therefore, it can be stated that it has some validity and credibility (Figure 1).

\section{Conclusion}

In conclusion, we demonstrated that there was a small (1.89\%) frequency of complications occurring in 10,063 patients needle EMG during a period of twenty years and the complications were not significantly explained by patients past medical history. Overall, EMG procedures are relatively safe given that the procedure is followed by a standard method. Even though minor complications (discomfort, bleeding) are common, major complications (pneumothorax) are rare and very uncommon. Overall, there is not enough research done in the past regarding this similar issue and more studies are needed to contribute to our research.

\section{Ethical Statement}

We confirm that we have read the Journal's position on issues involved in ethical publication and affirm that this report is consistent with those guidelines.

\section{References}

1. Al-Shekhlee A, Shapiro BE, Preston DC (2003) Iatrogenic complications and risks of nerve conduction studies and needle electromyography. Muscle Nerve 27(5): 517-526.
2. Hawley RJ (2000) Preventing complications of electromyography. Electromyogr Clin Neurophysiol 40(6): 323-325.

3. Purewal TS, Watkins PJ (1995) Postural hypotension in diabetic autonomic neuropathy: a review Diabet Med 12(3): 192-200.

4. Schoenberger JA (1991) Drug-induced orthostatic hypotension. Drug Saf 6(6): 402-457.

5. Atkins D, Hanusa B, Sefcik T, Kapoor W (1991) Syncope and orthostatic hypotension. Am J Med 91(2): 179-185.

6. Mohamed H (2008) Syncope: Evaluation and management. Libyan J Med 3(3): 156-159.

7. Seger JJ (2005) Syncope Evaluation and Management. Tex Heart Inst J 32(2): 204-206.

8. Park J, Jang SY, Yim HR, On YK, Huh J, et al. (2010) Gender difference in patients with recurrent neurally mediated syncope. Yonsei Med J 51(4): 499-503.

9. Kassardjian CD, O gorman CM, Sorenson EJ (2016) The risk of iatrogenic pneumothorax after electromyography. Muscle Nerve 53(4): 518-521.

10. Sander HW, Quinto CM, Murali R, Chokroverty S (1997) Needle cervical root stimulation may be complicated by pneumothorax. Neurology 48(1): 288-289.

11. Reinstein L, Twardzik FG, Mech JK (1987) Pneumothorax: a complication of needle electromyography of the supraspinatus muscle. Arch Phys Med Rehabil 68(9): 561-562.

12. Honet JE, Honet JC, Cascade P (1986) Pneumothorax after electromyographic electrode insertion in the paracervical muscles: case report and radiographic analysis. Arch Phys Med Rehabil 67(9): 601-603.

13. Mateen FJ, Grant IA, Sorenson EJ (2008) Needlestick injuries among electromyographers. Muscle Nerve 38(6): 1541-1545.

14. Gechev A, Kane NM, Koltzenburg M, Rao DG, van der Star R (2016) Potential risks of iatrogenic complications of nerve conduction studies (NCS) and electromyography (EMG). Clinical Neurophysiology Pract 1: $62-66$.

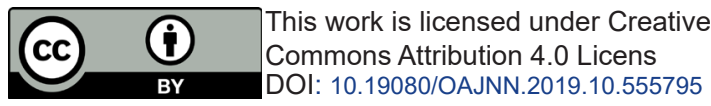

\begin{tabular}{l} 
Your next submission with Juniper Publishers \\
will reach you the below assets \\
- Quality Editorial service \\
- Swift Peer Review \\
- Reprints availability \\
- E-prints Service \\
- Manuscript Podcast for convenient understanding \\
- Global attainment for your research \\
- Manuscript accessibility in different formats \\
( Pdf, E-pub, Full Text, Audio) \\
- Unceasing customer service \\
Track the below URL for one-step submission \\
https://juniperpublishers.com/online-submission.php \\
\hline
\end{tabular}

